\title{
2D and 3D characterization of rolling contact fatigue cracks in manganese steel wing rails from a crossing
}

Dhar, S.; Danielsen, Hilmar Kjartansson; Fæster, Søren; Rasmussen, Christian Jørgen; Juul Jensen, Dorte

\section{Published in:}

Wear

Link to article, DOI:

10.1016/j.wear.2019.202959

Publication date:

2019

Document Version

Peer reviewed version

Link back to DTU Orbit

Citation (APA):

Dhar, S., Danielsen, H. K., Fæster, S., Rasmussen, C. J., \& Juul Jensen, D. (2019). 2D and 3D characterization of rolling contact fatigue cracks in manganese steel wing rails from a crossing. Wear, 436-437, [202959]. https://doi.org/10.1016/j.wear.2019.202959

\section{General rights}

Copyright and moral rights for the publications made accessible in the public portal are retained by the authors and/or other copyright owners and it is a condition of accessing publications that users recognise and abide by the legal requirements associated with these rights.

- Users may download and print one copy of any publication from the public portal for the purpose of private study or research.

- You may not further distribute the material or use it for any profit-making activity or commercial gain

- You may freely distribute the URL identifying the publication in the public portal 


\title{
2D AND 3D CHARACTERIZATION OF ROLLING CONTACT FATIGUE CRACKS IN A MANGANESE STEEL WING RAILS FROM A CROSSING
}

\author{
S Dhar ${ }^{* *}$, HK Danielsen ${ }^{1}$, S Fæster ${ }^{1}$, CJ Rasmussen ${ }^{2}$ and D Juul Jensen ${ }^{3}$ \\ ${ }^{1}$ Department of Wind Energy, Technical University of Denmark, Risø Campus, Roskilde, DK- 4000, Denmark \\ ${ }^{2}$ Banedanmark, Amerika plads 15, Copenhagen, DK-2100, Denmark \\ ${ }^{3}$ Department of Mechanical Engineering, Technical University of Denmark, Kgs. Lyngby, DK- 2800, Denmark \\ *E-mail: sodh@dtu.dk
}

\begin{abstract}
Rail wheel contact at switches and crossings (S\&Cs) induces impact stresses along with normal and shear contact stresses, resulting in plastic deformation and eventually crack formation. Damaged and deformed wing rails of a manganese steel crossing are studied and the microstructure, hardness and 3D crack network within the steel are characterized. The surface of the rail receives the maximum deformation resulting in a hardened top layer. The deformation is manifested in a high density of twins and dislocation boundaries in the microstructure. A complex crack network is revealed in high resolution by X-ray tomography.
\end{abstract}

Keywords: Switches and crossings (S\&Cs); deformation; 3D X-Ray tomography; 2D \& 3D crack network; rolling contact fatigue (RCF); manganese steel

\section{Introduction}

Switches and crossings (S\&Cs) are more susceptible to damage compared to normal tracks because of their moving parts and complex geometry. Therefore, poorly maintained S\&Cs encounter frequent failures and large maintenance cost. The direction of traffic plays an important role in the damage evolution in the crossing. When a wheel passes from the nose to the wing rail or vice versa, the component suffers from high impact stresses as well as rolling contact stresses causing severe damage like fatigue cracks and spallation if proper maintenance is not performed [1].

Pearlitic steels are most commonly used in normal tracks as well as in crossings. Although swing nose crossings with less impact levels can be used for heavy haul and high speed systems, in recent years manganese steel has been the preferred choice for fixed crossings because of superior mechanical properties. Most studies on deformation and cracks in rail steels are done for pearlitic steel taken from normal tracks [2-8]. Not much work has been published in the literature on the damage and degradation behaviour of manganese steel crossings, in contrast to the use of manganese steel in abrasive wear applications such as rock crushing equipment. In a previous work [9] we investigated the nose of a manganese steel crossing which was in service in the Danish rail network for five years. The direction of traffic was mostly towards the nose and hence the nose was severely damaged with cracking and visual spallation. A complex crack network had developed in the nose, which is similar to crack networks developed in pearlitic steels in straight track although the microstructural characteristics and deformation mode in the two steels are very different. It was obvious that the nose was heavily deformed due to rolling contact stresses as well as impact stresses. Deformation causes formation of twins and dislocation boundaries in the austenitic grains near the surface, but no shearing of grains was observed.

The wing rails can also be heavily damaged when the direction of traffic is from the nose to the wing rail. In this case, the wing rail will suffer from impact loadings due to discontinuity in rail wheel contact at the transition zone. It is thus of interest to compare the damage and deformation of a wing rail to the nose rail. This is the main aim of the present work in which the damage and deformation of a manganese steel crossing has been investigated, focusing on the wing rails. The crossing investigated in this work was in service in the Danish rail network for 13 years with a yearly traffic density of 14 MGT (million tons) where more than $90 \%$ of the traffic was from the nose to the wing rail in a straight track; hence one of the wing rails was severely damaged by impacts and contained cracks. The experimental techniques used for the present investigation are the same as those used in the previous study for the crossing nose, namely characterization with optical microscopy and hardness measurements, as well as X-ray tomography for 3D mapping of the crack network. With X-ray tomography cracks can be mapped non-destructively and with good resolution compared to the traditional method of repeated grinding, polishing and imaging of the crack cross section by optical microscopy [9].

\section{Experimental Procedure}


The two wing rails of a manganese steel crossing were studied. Although nowadays most of the manganese steel crossings are explosion hardened for better mechanical properties, this one was not explosion hardened. Visual inspection showed the wing rails were heavily deformed and damaged, and the presence of repair welds was evident on one of the wing rails. A schematic diagram of a switch and crossing (S\&C) assembly is given in Figure 1a and 1b, which shows the position of the switch blades when the train is moving on to the diverging track or straight track respectively. Depending on the direction of the traffic, one of the wing rails or the nose will receive heavy impact. Figure 1c shows a schematic diagram of the crossing panel indicating the regions from where the parts of the crossing in Figure 1d and 1e are cut from. As wing rail 2 is repair welded, the samples were taken from the non-welded part next to the most severe impact zone where the wheels contact change from the nose to the wing rail.

Small samples for investigation were cut from the wing rails. Wing rail 2 (as well as the nose) had received extensive repair welding; no samples were taken from the welded sections. The micro hardness measurements on the transverse surface (TD, ND) of the wing rails at five different locations (as shown by roman numbers in Figure 1d and 1e) were conducted using a Vickers hardness measurement tester with a load of $1 \mathrm{~kg}$ and a dwell time of 20 seconds. The hardness map was constructed from a series of measurements, which were done from the rail wheel contact surface down to a depth of $10 \mathrm{~mm}$ with a step size of $0.3 \mathrm{~mm}$ and $1 \mathrm{~mm}$ along the normal and the transverse direction, respectively.

The deformed microstructure of the transverse section was studied using optical microscopy (OM). The samples were ground with $\mathrm{Si}-\mathrm{C}$ paper ranging from grain 220 to 4000 then polished with diamond paste down to $1 \mu \mathrm{m}$ and etched with Nital.

The crack network developed in the wing rail was studied by X-ray computerized tomography. For these measurements, samples having a cross section of $10 \mathrm{~mm}$ by $10 \mathrm{~mm}$ and $40 \mathrm{~mm}$ in length were cut out from the wing rail. A Zeiss Xradia Versa 520 was used for the measurements. A polychromatic X-ray beam with energies ranging up to $160 \mathrm{kV}$ from a tungsten target was used. A total of 1601 projections were acquired during a full sample rotation. 3D maps were reconstructed by a standard filtered back-projection method to $2 \mathrm{k} \times 2 \mathrm{k} \times 2 \mathrm{k}$ voxel volumes with a voxel size of $10 \mu \mathrm{m}^{3}$. The crack network was segmented and visualized by using the Avizo 3D software.

\section{Results}

\subsection{Hardness}

Figure 2 shows the hardness maps of the two wing rails at different locations. The positions (i), (iii) and (iv) belong to wing rail 1 and (ii) and (v) to wing rail 2, which had been repair welded. As shown, the hardness measurements were made on wing rail 2 at locations away from the weld. The figures show that the hardness gradient is different at different locations, due to the difference in rail wheel contact at those places. In positions (ii), (iv) and (v), the deformation hardening is most severe at the top layer showing a high hardness of more than $600 \mathrm{Hv}$. The hardness maps from locations (i) and (iii) show that these locations are comparatively less deformed. The extent of deformation varies due to the difference in the direction of traffic (diverging track or straight track). Below the wheel running surface the hardness values decrease, indicating less deformation at larger depths, with the undeformed region having a base hardness of around $220 \mathrm{Hv}$. Cracks were found at region (ii), although the hardness as well as depth of hardening are higher at region (iv) and (v). No cracks were found in these very hard regions; (iv) and (v).

Region (i) has the least deformation and maintains the original rail profile shape, whereas in the other cases, the rail profile changes with deformation. With increased deformation, the depression of the surface profile (as in Figure $2 b, 2 d$ and 2e) compared to the original profile gets more severe. The work hardened layer is observed to extend to $10 \mathrm{~mm}$ below the surface. This depth of the deformation in the investigated wing rails is found to be nearly the same as found in case of the manganese nose rail studied previously [9]. Although the previously studied crossing was fairly a new one ( 5 years in service) compared to the crossing in the present study (13 years in service), the yearly traffic density through both the switches was approximately the same (14MGT). The depth of hardening was the same in both cases. Similar depth of hardening is reported for manganese crossing experiencing 130 MGT loads during service in another study [10]. Depth of hardening by other deformation mechanisms like explosion hardening can be much higher up to $25 \mathrm{~mm}$ from the surface [11]. The depth of hardening from wheel/rail contact is significantly higher in manganese grade crossings compared to normal pearlite grade. In literature it has been reported that in pearlitic grade the depth of hardening extends to only 3-5 $\mathrm{mm}$ from the wheel running surface [12-13]. 
(a)
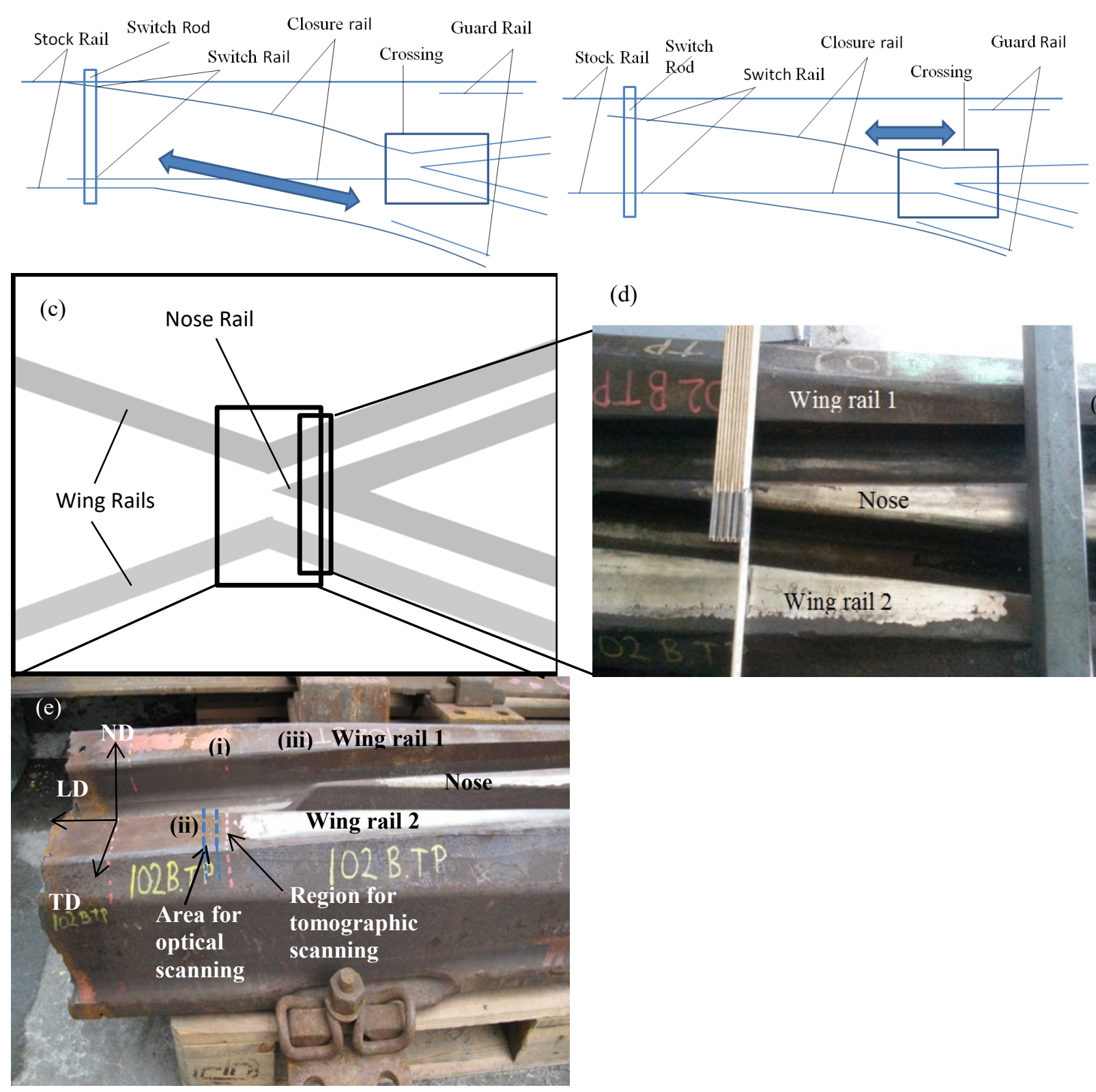

(b)

(d)

Figure 1: Schematic diagram of a railway switch and crossing showing the position of switch rails when the train moves on to the (a) diverging track and (b) straight track. (c) Schematic diagram of only the crossing panel showing the different components, with (d) and (e) showing the parts of the manganese steel crossing cut out for investigations. The roman numbers within the figure (in black) indicate the locations of hardness measurements. ND, TD, LD represents normal direction, transverse direction and longitudinal direction respectively.

\subsection{Microstructure}

The microstructure is austenitic in manganese steel. The grain size is coarse, ranging up to $500 \mu \mathrm{m}$, and the grains do not deform by shearing as in pearlitic rails. Figure 3(a-d) shows optical micrographs of the deformed wing rail at different depths from the wheel running surface. At the rolling contact surface, Figure $3 \mathrm{a}$, a large number of bands can be seen crossing each other within the grains. The deformation in manganese steels is manifested in the form of these bands and not by the usual elongation of grains as seen in pearlite. The surface receives the maximum deformation and hence the density of the bands is higher here and decreases with depth from the surface (Figures $3 a-d)$. At around 12 $\mathrm{mm}$ in depth (Figure 3d) the microstructure is almost free from deformation bands. The deformation bands are inhomogeneously distributed with a wavy appearance and the direction of the bands varies from one grain to another. From optical microcopy it is not possible to reveal whether the deformation bands are mechanical twins or dislocation boundaries. The deformed microstructure in the wing rail was found to be similar to the manganese nose rail 
investigated previously [9].

(a)
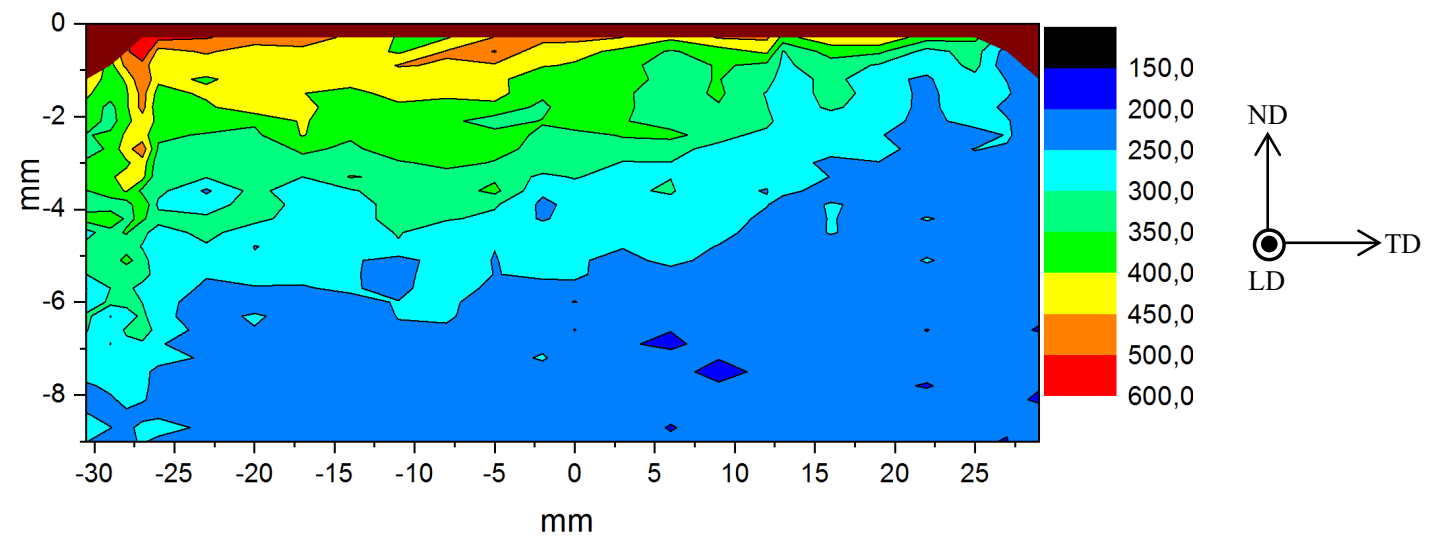

(b)

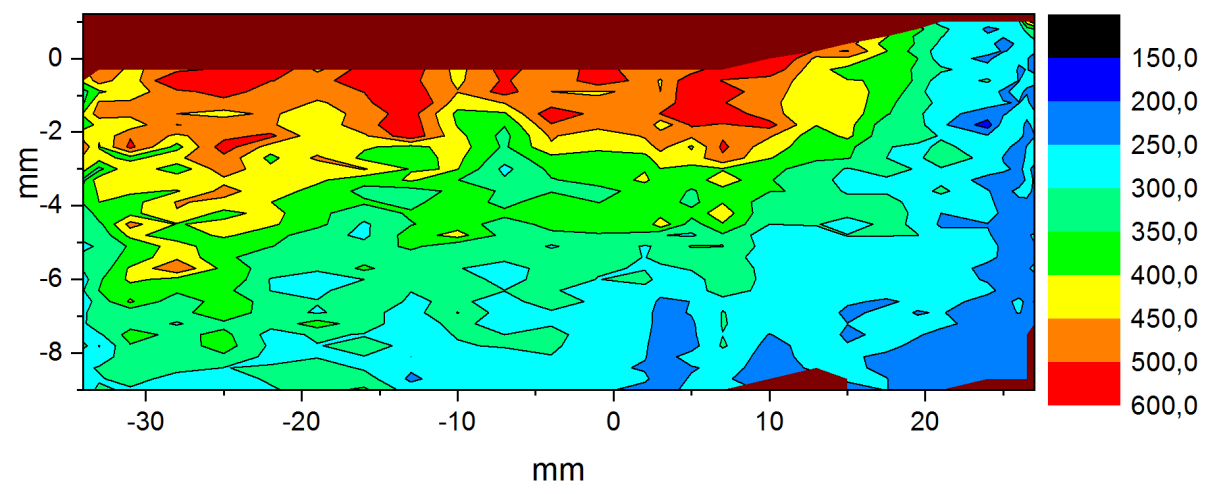

(c)

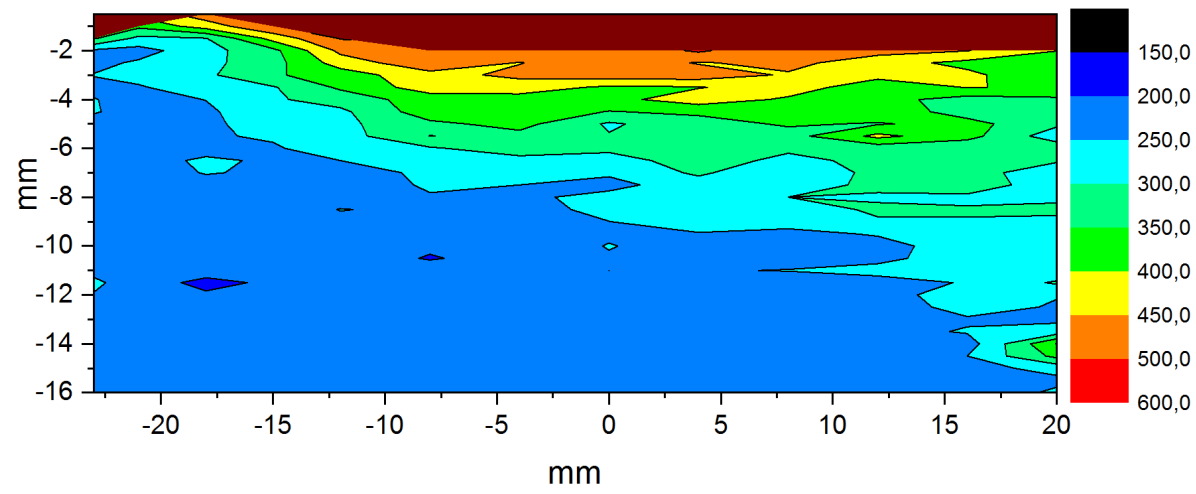

(d)

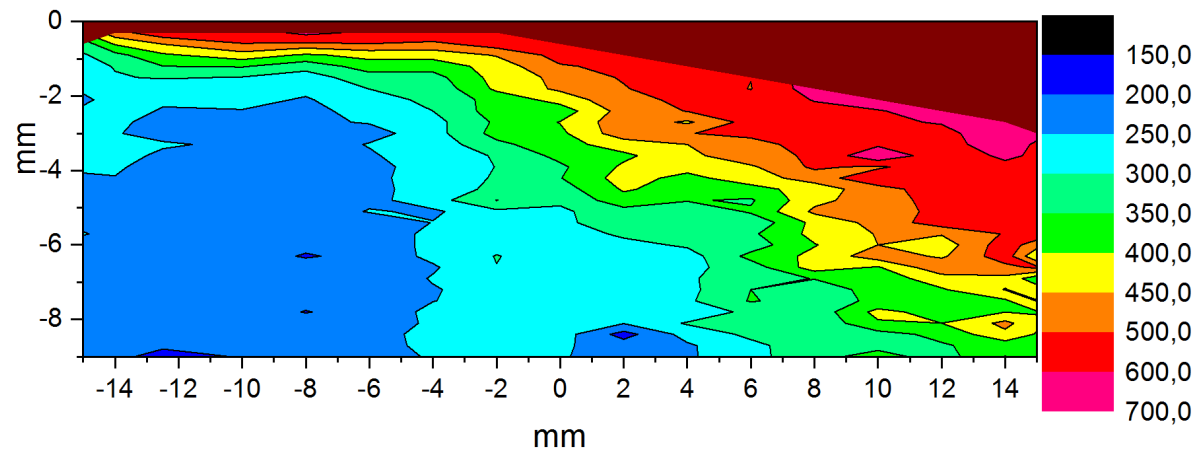




\section{(e)}

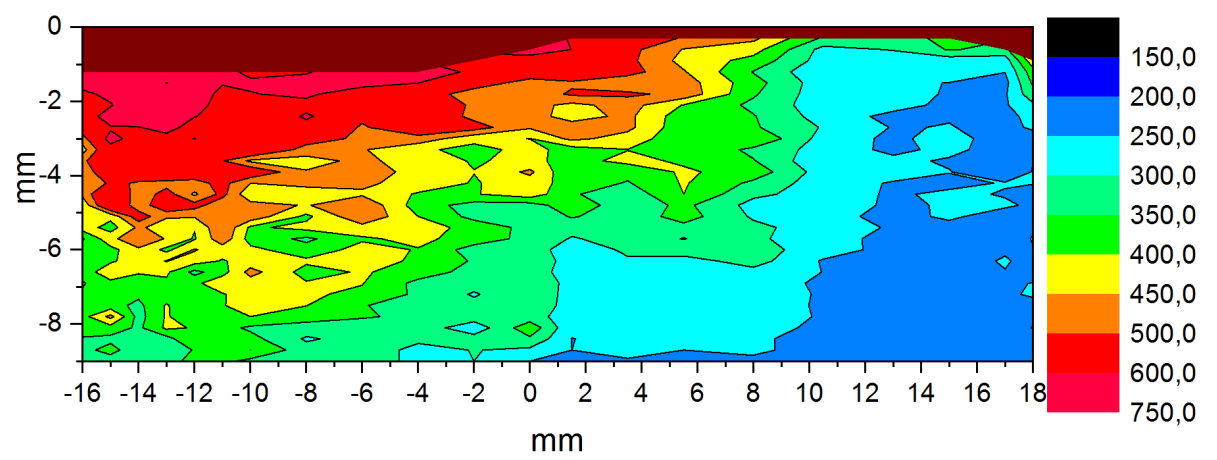

Figure 2: Hardness contour maps of the wing rails at different locations: (a) Wing rail 1 position i, (b) Wing rail 2 position ii, (c) Wing rail 1 position iii, (d) Wing rail 1 position iv and (e) Wing rail 2 position v. The axes only indicate the scale. The zero points are chosen arbitarily.
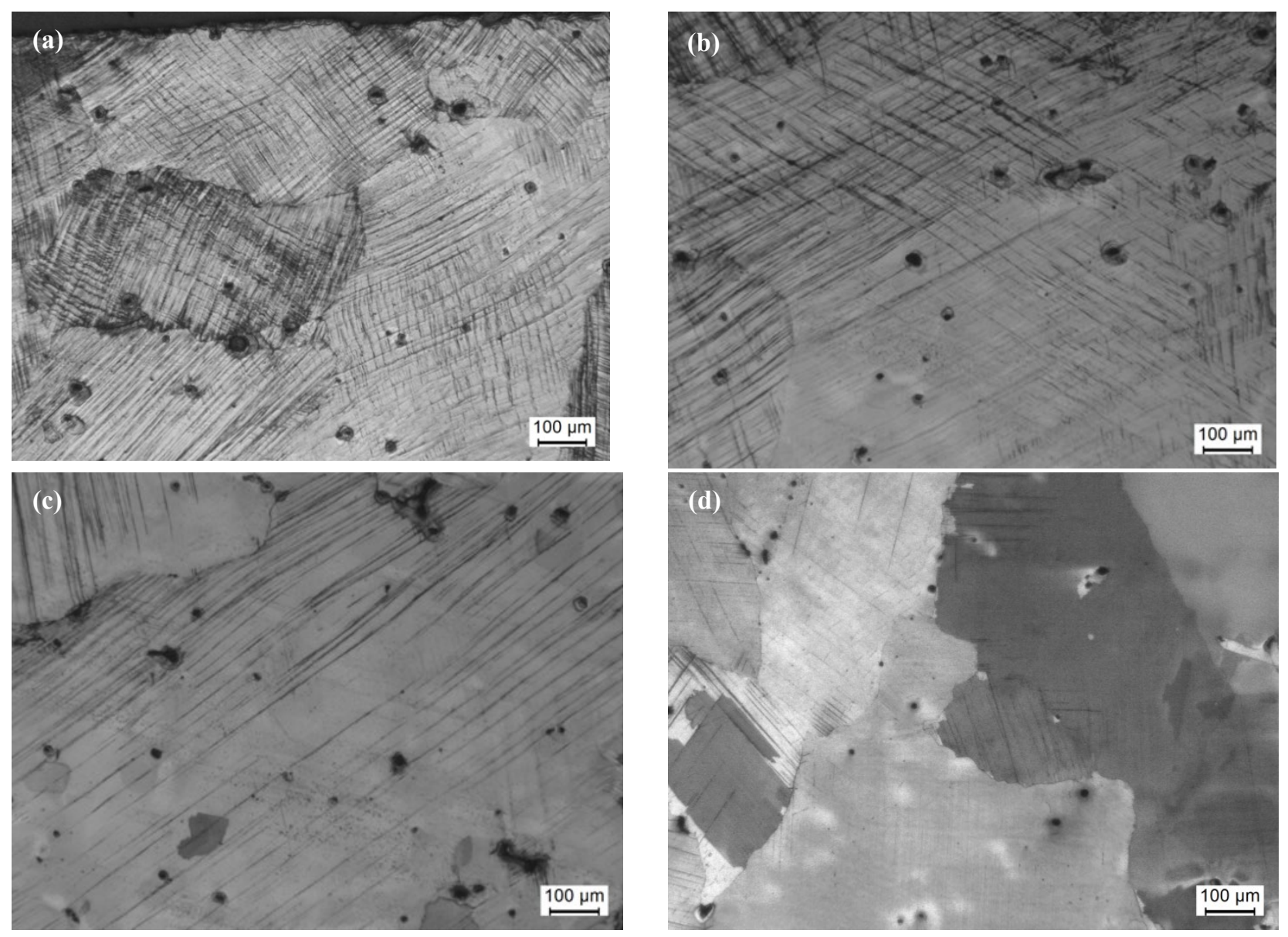

Figure 3: Optical microscopy images of the transverse section (a) at the rolling contact surface, (b) at $6 \mathrm{~mm}$ depth from the surface, (c) at $10 \mathrm{~mm}$ from the surface, and (d) at $12 \mathrm{~mm}$ from the surface, where the base hardness has been reached.

\section{$3.3 \mathrm{X}$-ray Computerized Tomography}

Two samples with size $10 \mathrm{~mm}$ by $10 \mathrm{~mm}$ by $40 \mathrm{~mm}$ from wing rail 2 (see Figure 1e) were characterized by X-ray tomography. Figure 4(a-d) shows $2 \mathrm{D}$ slices from one of the 3D tomographic reconstructions. Tomographical reconstructions are 3D density maps, which allow detection of even small cracks due to differences in density, thereby identifying cracks in 3D giving a detailed overview of the entire crack surface. Figure 4 shows a very long subsurface crack parallel to the running surface across the entire cross section of the specimen. However, the full 3D reconstruction also reveals the presence of cracks in contact with the surface. While most of the cracks run parallel to the running 
surface, the crack network is extensive and continuous.

Figure 5 shows the 3D reconstructions of another crack network in sample 2. In this figure, the steel is represented as transparent and the blue colored areas represent air, including air inside the cracks, thereby making the crack network and running surface visible. The white box represents the volume of the wing rail which has been scanned. The interior crack surface has a rough and wavy appearance with ridges which are quite similar to the failure surfaces often seen in rolling contact fatigue. Figure 5 also reveals that the crack network is spreading quite deep into the rail, with seemingly random crack propagation. Most of the cracks move parallel to the running surface, as apparent from Figure 4, but there are also some diverging downward branching cracks which could cause rail break in the long run. The wing rail contains both surface and sub surface cracks, where some are interconnected, and some propagate individually.
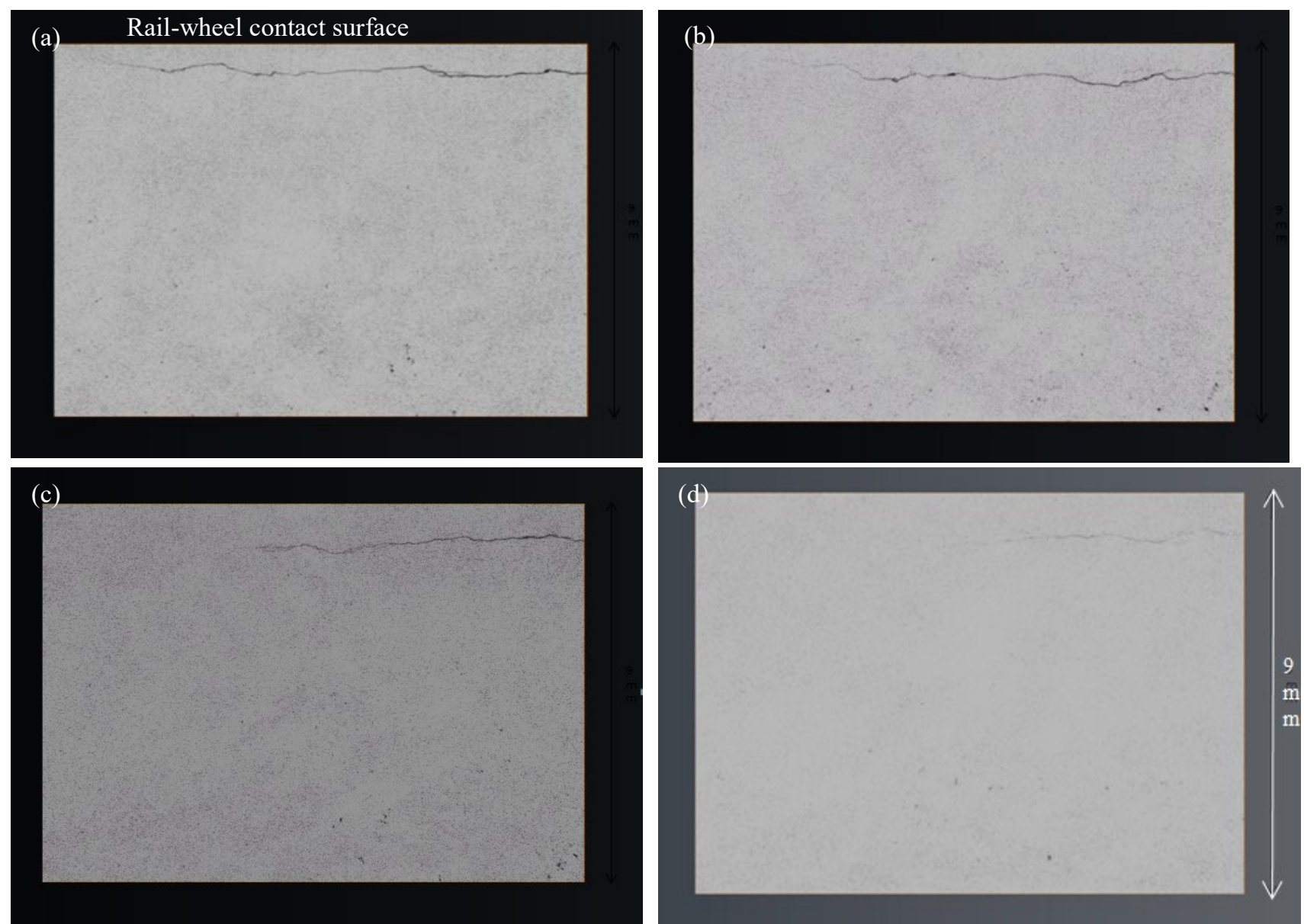

Figure 4: 2D slices showing the crack network within the wing rail at different locations along the longitudinal direction (a) at the trasverse cut $(0 \mathrm{~mm})$, (b) $10 \mathrm{~mm}$ from the transverse cut, (c) $18 \mathrm{~mm}$ from the transverse cut and (d) $29 \mathrm{~mm}$ from transverse cut. 

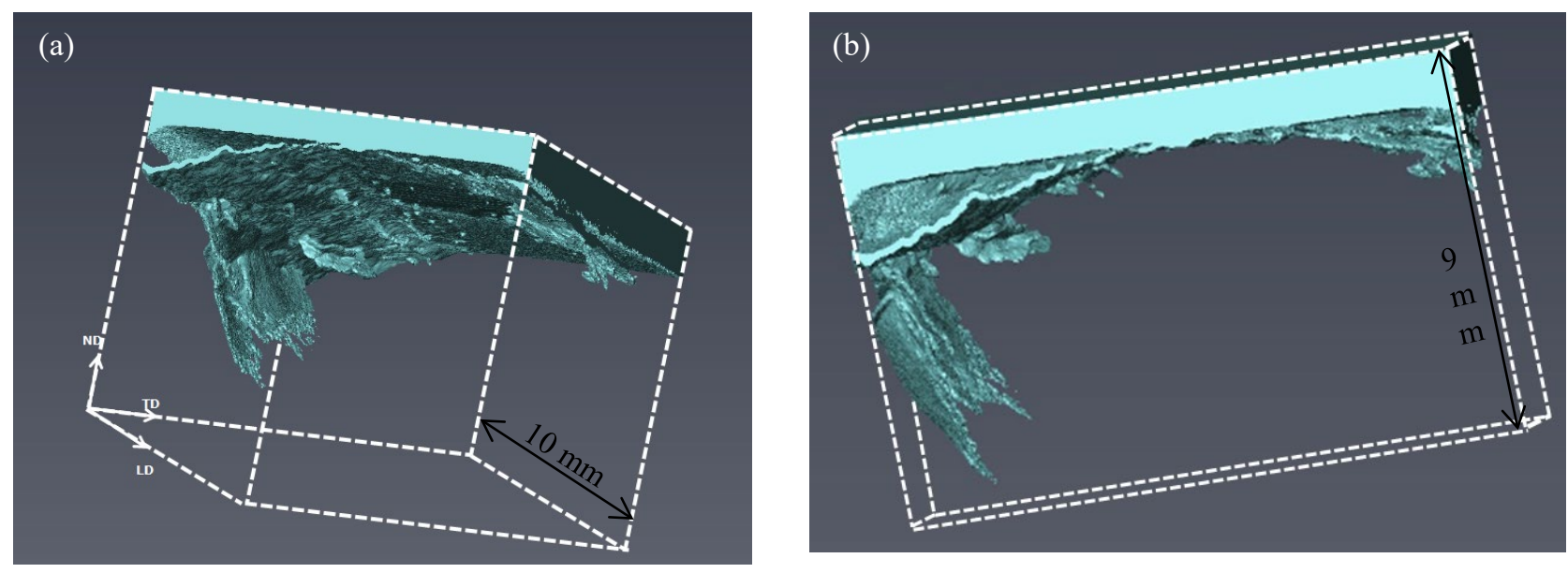

Figure 5: ( $a$ and b) 3-D tomographic representations of the crack network within the wing rail of a manganese crossing seen from different directions. The steel is represented as transparent and the blue coloured area represent air, making the crack network and running surface visible.

\section{Discussion}

The damage and deformation in the manganese wing rail is found to be quite similar to that in the manganese nose rail studied previously [9]. Although the geometry of a wing rail is different from the nose, the microstructural characteristics are similar. The deformation is manifested in the formation of a high density of deformation bands. The depth of hardening in both cases reached as high as $10 \mathrm{~mm}$ from the rail running surface. In case of the nose rail, cracks were found in the highly deformed top surface layers having high hardness of $600 \mathrm{Hv}$. In this study it was found that locations on the wing rail having very high hardness, position iv and v, were crack free whereas cracks were mostly found in regions of comparatively less hardness, position ii. Therefore, high deformation cannot be the only reason for crack formation in switches and crossings. Rail wheel interaction induces both normal and shear contact stresses when a train moves over a crossing, however the change of rolling planes from wing rail to nose, or vice versa, introduces high impact stresses as well. Most likely it is the impact from the wheel that is the reason for crack formation.

The two-phase microstructure in a pearlite grade material, consisting of ferrite and cementite, affects the deformation mechanism and eventually the crack initiation and propagation [14], where cracks tend to propagate through the softer ferrite phase, resulting in a wavy appearance. Figure 6 shows a rolling contact fatigue crack in pearlite grade steel from a straight track with a wavy crack propagation that passes through several grains. Figure 7 shows an optical micrograph of a subsurface crack in the wing rail of the manganese steel crossing investigated in this work having the same wavy appearance intersecting several grains with several crack branches and a seemingly random crack propagation. This is in correspondence to the cracks found in a manganese steel crossing nose studied previously in [9], where a more detailed study showed the cracks avoided the twinned regions (harder areas of the matrix) and were mostly transgranular giving the wavy appearance by following the weakest link in the microstructure. Therefore, although the plastic deformation is caused by slip in pearlitic grade without twinning, and for manganese steel deformation is from both dislocation motion as well as twinning, the crack networks have a similar appearance for pearlitic steel straight tracks and manganese steel crossings irrespective of the very different loading conditions in the two cases.

\section{Conclusions}

The deformation and degradation of the wing rails of a damaged non-explosion hardened manganese steel crossing, which has been in service in the Danish rail network, was studied. More than $90 \%$ of the traffic through this crossing was in straight track, from the nose to the wing rails and hence one of the wing rails is severely damaged from impacts and cracks are present. Heavy deformation is evident with the formation of a high density of deformation bands at the running surface. The hardening reaches to a depth around $10 \mathrm{~mm}$ from the running surface, with the surface having a very high hardness of above $600 \mathrm{Hv}$ which gradually drops to a base hardness of $220 \mathrm{Hv}$. Cracks were not found at the locations with highest hardness, thus it is likely that the wheel impact causes the cracks and not the deformation. The nondestructive 3D mapping of the crack network using X-ray tomography reveals the crack network and its minute branches with high resolution. The presence of both surface and sub surface cracks is evident in the wing rail. Though the material and the deformation mechanism of the manganese steel is quite different from that of normal pearlitic grade steel, and the loading conditions are different as well, the crack network seems to be similar to rolling contact fatigue 
cracks found in pearlitic grade steel used in normal straight tracks. The cracks tend to be concentrated mostly within the plastically deformed layer and have a wavy surface appearance which is common for rolling contact fatigue cracks.

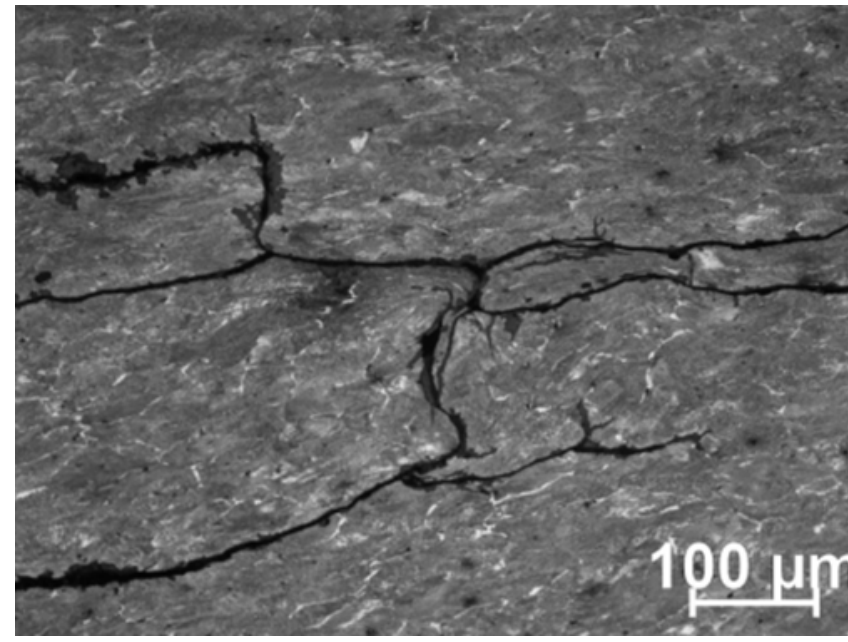

Figure 6: Optical micrograph of a rolling contact fatigue crack in a rail from straight track of pearlitic steel [15].

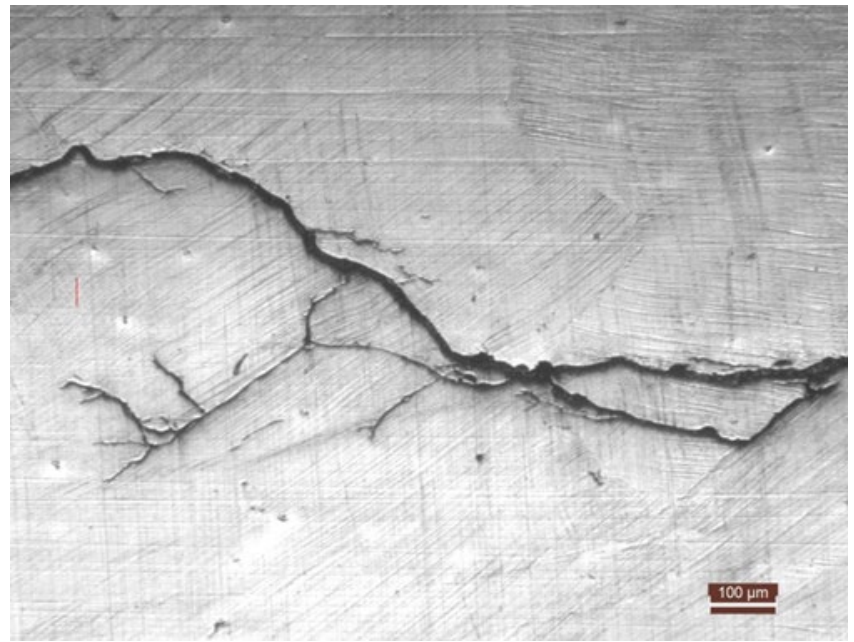

Figure 7: Optical micrograph of a rolling contact fatigue crack in the wing rail of manganese steel crossing.

\section{Acknowledgments}

The authors gratefully acknowledge support from the Innovation Fund Denmark through the project "INTELLISWITCH - Intelligent Quality Assessment of Railway Switches and Crossings" (Grant no 4109-00003B).

\section{References}

[1] B. Lv, M. Zhang, F. C. Zhang, C. L. Zheng, X. Y. Feng, L. H. Qian and X. B. Qin: Micro-mechanism of rolling contact fatigue in Hadfield steel crossing, International Journal of Fatigue, 2012, 44, 273-278.

[2] M. Schilke, N. Larijani and C. Persson: Interaction between cracks and microstructure in three dimensions for rolling contact fatigue, Fatigue and Fracture of Engineering Materials and Structures, 2014, 37, 280-289.

[3] C. Jessop, J. Ahlström, L. Hammar, S. Fæster and H. K. Danielsen: 3D characterization of rolling contact fatigue crack networks, Wear, 2016, 366-367, 392-400.

[4] Y. Zhou, X. Zheng, J. Jiang and D. Kuang: Modeling of rail head checks by X-ray computed tomography scan technology, International Journal of Fatigue, 2017, 100, 21-31.

[5] M. Steenbergen and R. Dollevoet: On the mechanism of squat formation on train rails - Part I: Origination, International Journal of Fatigue, 2013, 47, 361-372.

[6] M. Steenbergen and R. Dollevoet: On the mechanism of squat formation on train rails - Part II: Growth, International Journal of Fatigue, 2013, 47, 373-381.

[7] L. Wang, A. Pyzalla, W. Stadlbauer and E. A. Werner: Microstructure features on rolling surfaces of railway rails subjected to heavy loading, Materials and Engineering A, 2003, 359, 31-43.

[8] M. Masoumi, E. Anderson Ariza, A. Sinatora and H. Goldenstein: Role of crystallographic orientation and grain boundaries in fatigue crack propagation in used pearlitic rail steel, Materials and Engineering A, 2018, 722, 147155.

[9] S. Dhar, H. K. Danielsen, S. Fæster, C. Rasmussen, Y. Zhang and D. Juul Jensen: Crack formation within a Hadfield manganese steel crossing nose, Submitted to Journal of Wear.

[10] F. C. Zhang, B. Lv, T. S. Wang, C. L. Zheng, M. Zhang, H. H. Luo, H. Liu and A. Y. Xu: Explosion hardening of Hadfield steel crossing, Materials Science and Technology, 2010, 26:2, 223-229.

[11] S. L. Guo, D. Y. Sun, F. C. Zhang, X. Y. Feng and L. H. Qian: Damage of a Hadfield steel crossing due to wheel rolling impact passages, Wear, 2013, 305, 267-273.

[12] J. E. Garnham and C. L. Davis: Very early stage rolling contact fatigue crack growth in pearlitic rail steels, Wear, $2011,271,100-112$.

[13] H. C. Eden, J. E. Garnham and C. L. Davis: Influential microstructural changes on rolling contact fatigue crack initiation in pearlitic rail steels, Materials Science and Technology, 2007, 21(6), 623-629.

[14] F. D. Fischer, W. Daves, R. Pippan and P. Pointner: Some comments on surface cracks in rails, Fatigue and 
Fracture of Engineering Materials and Structures, 2008, 29, 938-948.

[15] M. Schilke: Degradation of railway rails from materials point of view, $\mathrm{PhD}$ Thesis, Department of Materials and Manufacturing Technology, Chalmers University of Technology, 2013, Sweden. 